could be used in an investigation of the structure of weak extended sources of light in interstellar space of the Milky Way. The Paul Instrument Fund Committee, composed of representatives of the Royal Society, the Physical Society, the Institute of Physics and the Institution of Electrical Engineers, was set up in 1945 "to receive applications from British subjects who are research workers in Great Britain for grants for the design, construction and maintenance of novel, unusual or much-improved types of physical instruments and apparatus for investigations in pure or applied physical science".

\section{Early Life of George Boole}

Sir GeOFFrey TAYLOR, whose mother was one of (')oorge Boole's daughters, contributes to Notes and Riecorls of the Royal Society, 12, 1, an article on Boole's early life and mathematical studies. Previous eccounts have not always been consistent one with another, nor entirely free from unwarranted speculation. Some interest is attached to these questions, since Boole's work on symbolic logic, first expounded in his "Mathematical Analysis of Logic" (1847) and developed more fully in his "Laws of Thought" (1854), is marked by profound originality of concept ; it gave one of the earliest instances of an algebra differing substantially from the familiar algebra of real numbers, and thus not only opened the way to a new field of applications, but also contributed largely to the development of modern ideas on the axiomatic foundations of a variety of abstract algebras. It is possible that this originality was fostered by the resolute manner in which Boole taught, himself mathematics, and that the months spent in surmounting difficulties which might have been cleared away in a few minutes by contact with a competent teacher were not entirely a waste of his time, but played a considerable part in forming a powerful and precise research mind. In the same issue of Notes and Records, W. Kneale discusses Boole's algebra of logic and its place in the history of mathematical logic.

\section{The Physics and Chemistry of Solids}

A NEW journal, The Physics and Chemistry of Solids, has been added to the international series published by the Pergamon Press (London: Pergamon Press, Ltd., 1956. 42s. each part. Subscription rates per volume (4 parts): $(A) £ 6 ; 17$ dollars); $(B)$ for individual subscribers certifying that the journal is for their private use, £2 15s.; 7.50 dollars). Prof. Harvey Brooks is editor-inchief; in his foreword to the first issue, a combined issue for September and October 1956, he defines the fields of physics and chemistry for which the journal is to cater. They are, first, the electronic structure of solids and those physical and chemical properties deriving from that structure; and secondly, the statistical mechanics of condensed systems. Fundamental studies will be preferred to applications; but papers on borderline subjects will, apparently, be welcomed rather than discouraged. The first issue sets a high standard, and the editors, who are drawn from the United States, the U.S.S.R., Holland and France, will secure a prominent position for the journal if they are able to maintain that standard aver the years; the advisory board, which includes the names of many whose contributions have greatly helped the advance of the understanding of the solid state, should ensure a steady flow of papers. The topics most to the fore in the first issue are magnetic properties, the absorption spectra of impurities in silicon, energy band-structure and residual resistivity. Two papers in particular contain good reviews of their parts of the subject-a feature which will be frequently required if the editors' aim of developing lines of communication between physicists and chemists is to be fulfilled.

\section{Archæology in India}

Tre October issue of Man contains an interesting article by Dr. F. K. Allchin on certain stone alignments in southern Hyderabad. Stone alignments are found at many times and in many parts of the world, and there is not necessarily any reason to suggest cultural connexions between them. In Hyderabad they only occur to the north of the Krishna and Tungabhadra Rivers in the Raichur, Gulbarga, Nalgonda, Mahbubnagar and Atraf-i-Balda districts of the State. They consist of parallel lines of standing stones set out accurately. In all cases the lines seem to be oriented on the cardinal points. It is suggested that their age is late B.C. or early A.D. In the same issue is an interesting article by Prof. Robert Heine Geldern on the coming of the Aryans and the end of the Harappa civilization in India. It is illustrated with a number of drawings of tools and seals. Prof. Heine-Geldern is convinced that the invaders arrived between 1200 and 1000 B.C., a date somewhat later than that usually suggested and much later than the one indicated in the subsequent (November) number of Man. The early archæology of the region from Quetta in Baluchistan right across northern India continues to excite great interest, and some day a firm date for the various eultures found will be finally determined.

\section{Alexander Graham Bell Museum, Nova Scotia}

The Alexander Graham Bell Museum, which the Canadian Government has established to illustrate the scientific achievements of the inventor of the telephone, was opened on August 18 at Baddeck, Nova Scotia, where Bell spent his summers for more than thirty years and participated in early aeronautical research. The Museum is sponsored by the Department of Northern Affairs and National Resources, and its purpose is to protect and display the numerous relics of Bell's research that have been given to the Canadian Government. Kites, propellers and other objects indicate the experiments in heavierthan-air flight which Bell carried out between 1896 and 1909, while other material illustrates his investigations in medicine and electrical and marine engineering.

\section{The Industrial Research Associations in Great Britain}

THE Department of Scientific and Industrial Research has issued an admirably illustrated account of the work of the industrial research associations in the government scheme in a booklet entitled "Combining for Research : the Work of the Industrial Research Associations in the Government Scheme" (pp. $32+16$ plates; from the Department, London; 1956). The booklet outlines the naturo of the research associations as well as describing the various types of work carried out, and includes brief notes on tho individual research associations. While in no way critical, and making no attempt to assess the relative importance or value of the different activities, it indicates very clearly the potentialities of co-operative research as well as the conditions which must be fulfilled for effective work. 